\title{
Putting a stop to feeding
}

\section{ce}

\section{This study}

shows that $\mathrm{CEI}$

$\mathrm{PKC} \delta^{+}$neurons

are crucial

players in the

brain circuitry

that regulates

food intake
Satiety- and nausea-induced cues can inhibit feeding, but the neural circuits that underlie these regulatory mechanisms remain to be elucidated. In a new study, Anderson and colleagues identify a subpopulation of neurons in a subdivision of the central amygdala - whose role in feeding has been controversial that mediate diverse anorexigenic signals.

Cholecystokinin (CCK) - which induces satiety - and lithium chloride $(\mathrm{LiCl})$ - which induces nausea

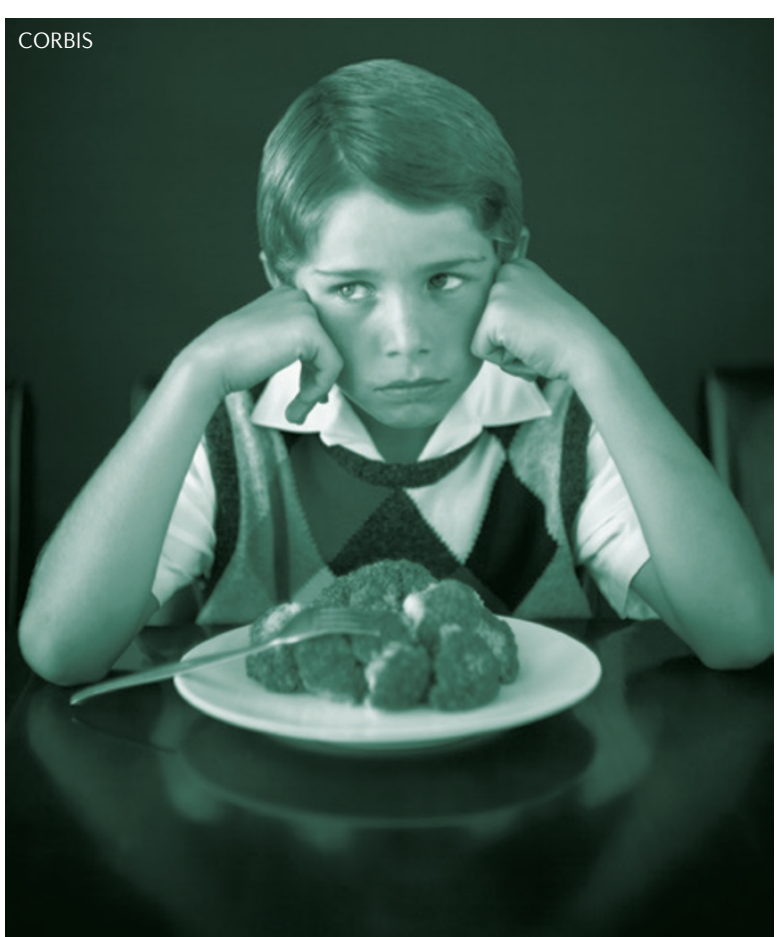

— inhibit feeding behaviour in fasting mice. The authors found that intraperitoneal injections of CCK or $\mathrm{LiCl}$ in mice induced the expression of FOS (a marker of neuronal activity) in neurons in the lateral central amygdala $(\mathrm{CEl})$ that express protein kinase $\mathrm{C} \delta$ (CEl $\mathrm{PKC} \delta^{+}$neurons). Moreover, pharmacogenetic silencing of $\mathrm{CEl} \mathrm{PKC} \delta^{+}$neurons restored feeding behaviour in CCK- or LiCltreated fasted mice, and increased feeding behaviour in untreated nonfasted mice. This suggests that such neurons mediate the anorexigenic effects of CCK and $\mathrm{LiCl}$.

To further examine this assertion, the authors investigated the effects of $\mathrm{CEl} \mathrm{PKC} \delta^{+}$neuron activation on feeding behaviour by selectively expressing channelrhodopsin 2 (ChR2) in these neurons. Light stimulation markedly inhibited food intake in ChR2-expressing fasted mice, with normal levels of feeding resuming when the light was turned off. Indeed, even mice in the act of eating stopped and put down their food a few seconds after the stimulus. Thus, $\mathrm{CEl} \mathrm{PKC}^{+}$neural activity suppresses feeding behaviour.

To examine the circuits by which the anorexigenic agents act, the authors used rabies-virus-based retrograde tracing from $\mathrm{CEl} \mathrm{PKC}{ }^{+}$ neurons in combination with FOS labelling in response to exposure to $\mathrm{LiCl}$ or CCK. In response to $\mathrm{LiCl}$, FOS expression could be detected in retrogradely traced neurons from the lateral parabrachial nucleus (LPB), basolateral amygdala (BLA) and the insula. However, in response to CCK, FOS expression was only detected in the retrogradely traced neurons in the LPB and BLA. This suggests that different anorexigenic agents activate different brain areas but that anorexigenic signals converge on $\mathrm{CEl} \mathrm{PKC} \delta^{+}$neurons.

Using an optogenetic circuitmapping approach, the axons of $\mathrm{CEl} \mathrm{PKC} \delta^{+}$neurons were found to form GABAergic synapses in several areas, including onto $\mathrm{PKC} \delta^{-}$ neurons in the central amygdala. Optogenetic silencing of these $\mathrm{PKC}^{-}$neurons suppressed the food intake of fasted mice, whereas optogenetic activation of these cells attenuated CCK-induced inhibitory effects on feeding.

This study shows that CEl PKC $\delta^{+}$neurons are crucial players in the brain circuitry that regulates food intake. Although it is not yet clear what the long-term effects of activating or silencing these neurons might be, these findings may have important implications in the understanding of eating disorders.

Natasha Bray

ORIGINAL RESEARCH PAPER Cai, H. et al. Central amygdala PKC $-\delta^{+}$neurons mediate the influence of multiple anorexigenic signals. Nature Neurosci. http://dx.doi.org/10.1038/nn.3767 (2014) 